\title{
VAN DÜLMEN, Richard, Kultur und Alltag in der frühen Neuzeit, t. 2: Dorf und Stadt, München
}

\section{Gérald Chaix}

\section{OpenEdition}

\section{Journals}

Édition électronique

URL : http://journals.openedition.org/ifha/2084

DOI : 10.4000/ifha.2084

ISSN : 2198-8943

\section{Éditeur}

IFRA - Institut franco-allemand (sciences historiques et sociales)

\section{Référence électronique}

Gérald Chaix, «VAN DÜLMEN, Richard, Kultur und Alltag in der frühen Neuzeit, t. 2: Dorf und Stadt, München », Revue de l'IFHA [En ligne], Date de recension, mis en ligne le 01 janvier 1993, consulté le 22 septembre 2020. URL : http://journals.openedition.org/ifha/2084 ; DOI : https://doi.org/10.4000/ifha. 2084

Ce document a été généré automatiquement le 22 septembre 2020.

(C)IFHA 


\title{
VAN DÜLMEN, Richard, Kultur und Alltag in der frühen Neuzeit, t. 2: Dorf und Stadt, München
}

\author{
Gérald Chaix
}

1 Voici le second des trois volumes consacré par R.v.D. à l'histoire de la vie quotidienne et de la civilisation matérielle dans l'Allemagne de la première modernité. Il traite cette fois du village et de la ville et présente les mêmes qualités que le volume précédent: une très grande maîtrise dans l'équilibre des chapitres et une parfaite lisibilité (qui n'exclut pas une analyse conceptuelle précise), un recours permanent à une information de première main (documents imprimés, archives judiciaires) et à une riche illustration, le souci de faire apparaitre les évolutions et de les expliquer, des renvois abondants aux travaux antérieurs, et une excellente bibliographie.

2 L'A. a réparti sa matière en cinq chapitres. Le premier est consacré à la vie au village, examinée sous trois éclairages: 1) un espace et ses habitants, aux profils sociaux très différenciés, non seulement au sein de la paysannerie mais aussi parmi la population rurale (domestiques, journaliers, artisans ruraux - forgerons, meuniers, savetiers, tanneurs et tisserands - et travailleurs à domicile - présents dès le XVIe siècle mais dont le nombre croit surtout au XVIIIe; 2) les travaux et les jours de la campagne: agriculture, élevage et artisanat rural (travailleurs à domicile et artisans); 3) le fonctionnement des communautés rurales fondé tout à la fois sur une relative autonomie interne et sur une dépendance certaine à l'égard des pouvoirs extérieurs (Etat et Eglises principalement). Selon R.v.D. les communautés rurales auraient connu entre le XVIe et le XVIIIe siècle une aggravation des clivages sociaux, un renforcement des pouvoirs extérieurs, et une dégradation de leurs particularités culturelles.

3 Le second est consacré à la vie urbaine, scrutée selon le même schéma que précédemment: l'espace urbain et ses habitants (assez traditionnellement répartis selon le modèle tripartite d'E. Maschke: Oberschicht, Mittelschicht, Unterschicht, auxquelles on ajoute une quatrième couche sociale regroupant les pauvres et les marginaux), le commerce et l'artisanat (et l'organisation en corporations, qui ne 
deviennent des freins au progrès qu'à partir du XVIIIe siècle), et l'organisation politique qui évolue successivement sous l'influence de la Réformation, de la guerre de Trente Ans et de l'absolutisme territorial, étapes auxquelles correspondent en gros les quatre vagues de révoltes populaires, celle contemporaine de l'établissement de la Réformation, celle du XVIe siècle finissant et des débuts du XVIIe siècle, celle des années 1660, au lendemain de la guerre de Trente Ans, et celle de la fin du XVIIIe siècle.

Le troisième traite de la sociabilité et des fêtes qui tiennent une place très importante dans la vie des gens. L'A. y analyse d'abord la sociabilité et ses usages (le jeu, la boisson, la danse et la musique, ainsi que le rôle des auberges que la noblesse tend progressivement à déserter; le calendrier des fêtes et les rituels qui scandent la vie des individus), soumis par delà les différences confessionnelles à un « processus civilisateur ». Puis, il étudie ces temps privilégiés que sont les marchés et le carnaval. Enfin, il consacre un paragraphe aux fêtes de cour.

5 Le quatrième examine les statuts sociaux (analysables selon l'A. à l'aide de cinq paramètres: biens et possessions, activité, influence politique, origine familiale, comportement public) et la notion d'honneur (à laquelle R.v.D. consacre de très belles pages, qui doivent évidemment beaucoup à $\mathrm{A}$. Grießinger et à $\mathrm{M}$. Dinges et par delà à $\mathrm{P}$. Bourdieu et à A. Farge), insistant bien sûr sur le caractère inégalitaire de la société d'Ancien Régime mais aussi sur les stratégies " honorifiques ", avant d'aborder l'évolution qui, selon lui, conduit de la société d'ordres (Ständeordnung) à la société bourgeoise (bürgerliche Gesellschaft).

6 Le cinquième aborde les notions d'ordre public et de conflits sociaux. R.v.D. y étudie l'opposition entre l'autonomie des ordres et la réglementation étatique qui tend à s'étendre à tous les domaines (réglementation de la vie économique, contrôle des fêtes et des conduites conjugales, moralisation des conduites et lutte contre l'oisiveté, organisation de la santé publique et de l'effort éducatif, contrôle des pratiques religieuses), entraînant une redéfinition des sphères de la vie privée et de la vie publique que l'on observe par exemple à travers l'effacement du système de domination patriarcale au profit du système du droit naturel. S'appuyant sur ses propres recherches et sur celles de ses élèves, il aborde ensuite le problème de la criminalité et des sanctions. Il conclut par une discussion de la notion de " procès de civilisation »- critiquant les oeuvres de M. Foucault, de N. Elias et de M. Weber - qu'il tend à repousser au profit de la notion plus large de contrôle social. Il propose enfin de distinguer trois formations culturelles: celle du peuple (qui passe la notion de culture populaire), celle de la noblesse et celle de la bourgeoisie.

7 Un beau travail - parfois un peu simplificateur, mais c'est l'inévitable revers d'un grand effort didactique - qui mériterait de figurer dans toutes les bibliothèques et qui fait attendre avec impatience le troisième volume. 